\title{
Estimation of the stress state of agricultural harrows with vertical axis rotor, using mathematical models with finite elements
}

\author{
Valentin Cornel Iordache ${ }^{1, *}$, Ion Saracin ${ }^{1}$ \\ ${ }^{1,}$ University of Craiova,Romania
}

\begin{abstract}
In this paper we simulated through mathematical models the interaction between the agricultural harrow with vertical rotor (equipped with 4 boxes per rotor) and soil. Due to the large or even very large number of mathematical models that can be developed and can receive a solution using the finite element method, there are also many new possibilities to approach and improve some already developed models. The most important benefits of using finite element modeling are: increasing the quality of projects by checking the resistance, noticing dangerous vibration problems, remedying deficiencies reported in the testing of experimental models or even in operation. Normal optimization aims to reduce material consumption, its own vibration spectrum or other mechanical qualities.By using mathematical methods, a resistance check of the subassemblies of the working member (knife), connected to the action device, is obtained.
\end{abstract}

\section{Introduction}

In this paper we will approach a slightly more complicated model, which contains in addition to four knives and a ring for fixing the knives to the drive system. In addition, the knives do not have the simplest shape, but have the shape of a curved bar that shapes (approximately) the shape of the knives of the agricultural harrow with vertical rotor[7], which can be observed in detail in fig.1. The simplest possible model could be the knife (working organ), simple organ, most often in the form of a bar fixed rigidly at one end and actuated laterally and frontally in the cycloidal direction of the knife.

The geometry of the model, the orientation and the elements of discretization (nodes and finite elements), are presented in fig. 2. The finite elements used are all Tymoshenko type bars, with the characteristics given in the documentation of the COSMOS / M 2.8 program, used for this modeling, [4.8].

In fig. 3 is show the structural model including boundary conditions (connection to the environment or fixation) and loading (forces)[5]. The fixing is done by canceling all the six components of the displacement (three translations and three rotations) in four nodes located equidistant in relation to the nodes in which the working organs (knives) are

\footnotetext{
* Corresponding author: valentin jordache@yahoo.com
} 
connected on the ring[2.3]. The loads of $100 \mathrm{~N}$ on each knife are evenly distributed along the length of the lower segment of the knife, a length which, in this example, represents the working depth[1.6]. The forces are oriented in the tangent direction to the circles on which the knife points rotate, simulating the reaction of the ground on the knives when the difference between the mechanical characteristics of the ground through which the knives did not pass and those of the ground through which the knives passed is not taken into account. There are also alternatives closer to reality for loading knives. Given the low speed of movement of the aggregate, it can be hypothesized that on a portion of a quarter circle from the tractor, the knives process hard soil, on the sides work in partially processed soil, and behind the equipment work in already processed soil. With the help of this hypothesis, results closer to reality are obtained. However, the hypothesis used in this article is more covering, taking into account the harsh regime of knife operation (shocks and intense friction).

The structural models presented in this paper are three-dimensional, combined with finite elements of bar type and solid type. The main purpose of these mathematical models is to estimate as close as possible to reality, the stress state of the knifes material, in the context in which experimental validation on knives is difficult to achieve.

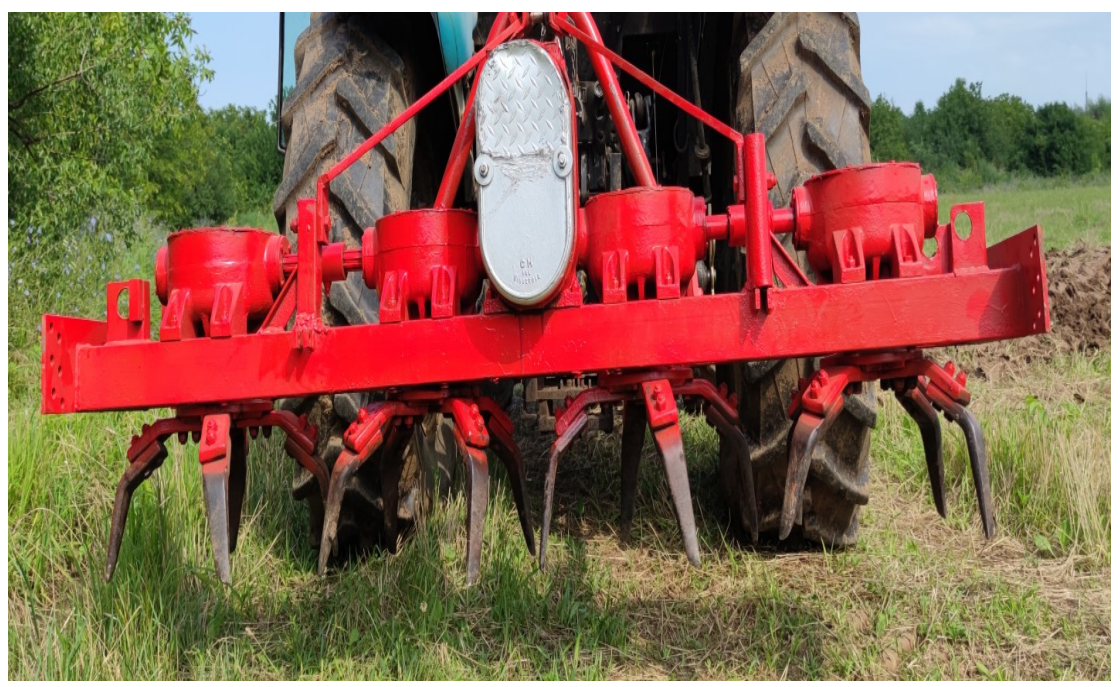

Fig. 1. Detail of the four rotors that equip the agricultural harrow with vertical rotors.

\section{Materials and methods}

The material analyzed in the article consists of the agricultural harrow with vertical rotor (fig.1), formed by working organs (knives), connected to their rotation system.

The analyzed harrow has four rotors that can be equipped with two, three or 4 knives per rotor. The dimensioning of the main dimensions used for the abstraction of the puree model with 1D bar finite elements and for the geometric construction of the puree model with solid finite elements (3D) is observed in fig. 4. A detail of the working element is presented in fig. 3 . 


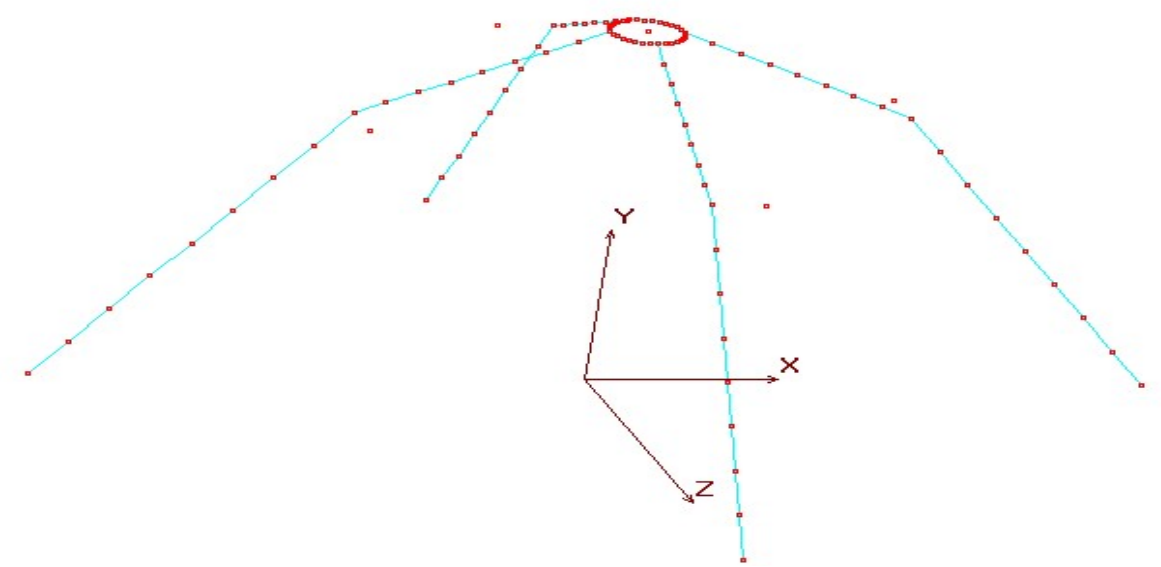

Fig. 2. The structural model of the rotor subassembly formed by knives and a connection ring with the motion transmission system.

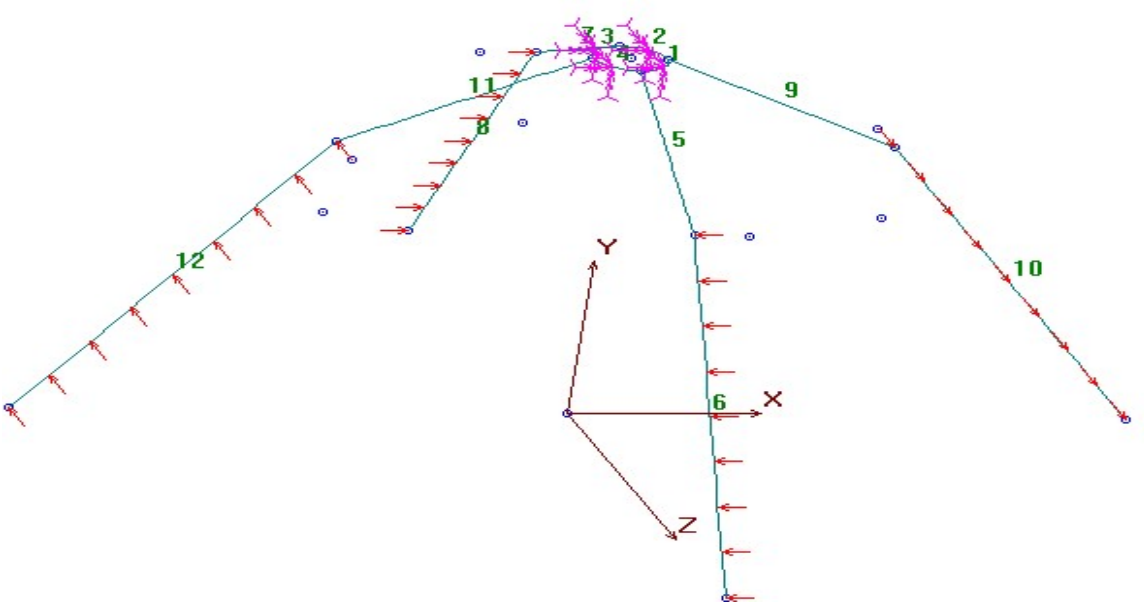

Fig. 3 The structural model of the rotor subassembly formed by knives and a connection ring with the motion transmission system. fig. 4.

The geometry of the mashed structural model with bar type elements, 1D, is given in For the structural model with 3D dimensional finite elements, the geometry is represented graphically in fig. 5. For the construction of the geometry, in the case of both models, we used values of the main dimensions defined in fig. 2 and $3: a_{1}=0.15 \mathrm{~m}, \mathrm{a}_{2}=0.2 \mathrm{~m}, \mathrm{~b}=$ $0.02 \mathrm{~m}, \mathrm{c}=0.05 \mathrm{~m}$. 


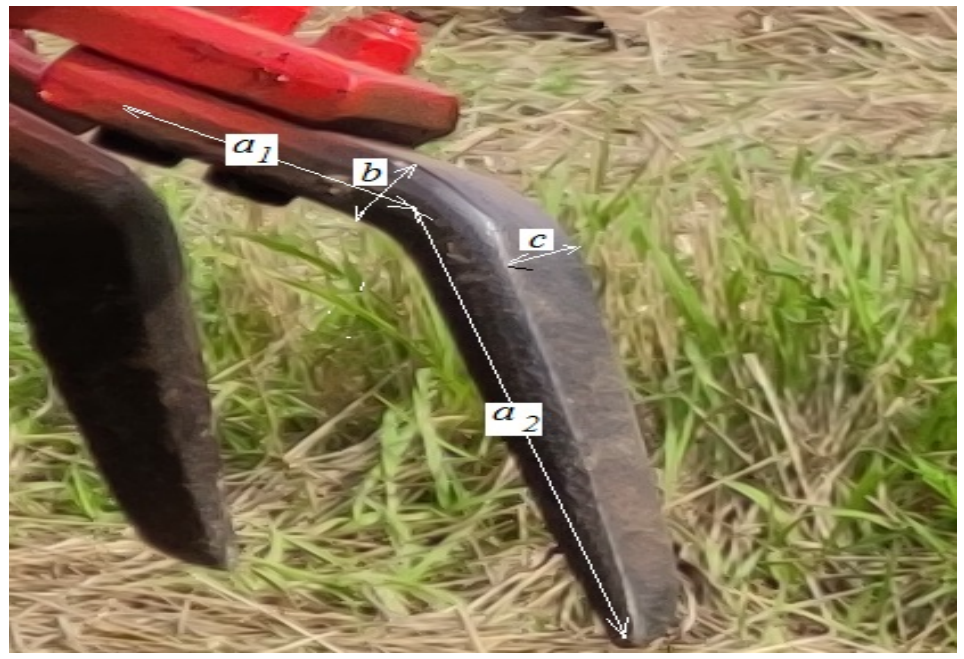

Fig. 4 Average dimensions for basic models

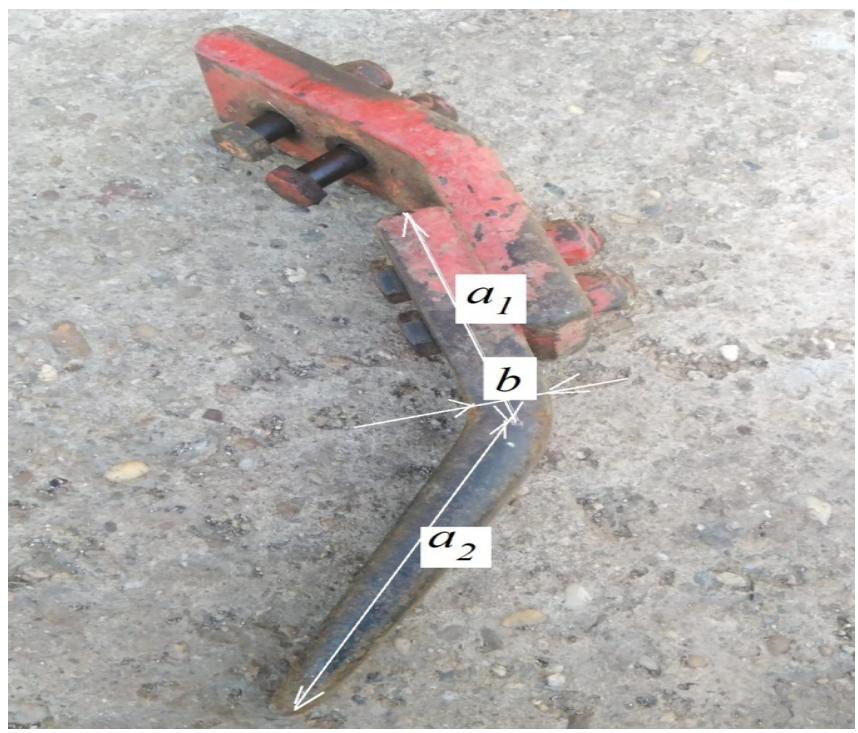

Fig. 5 Average dimensions for basic knife 


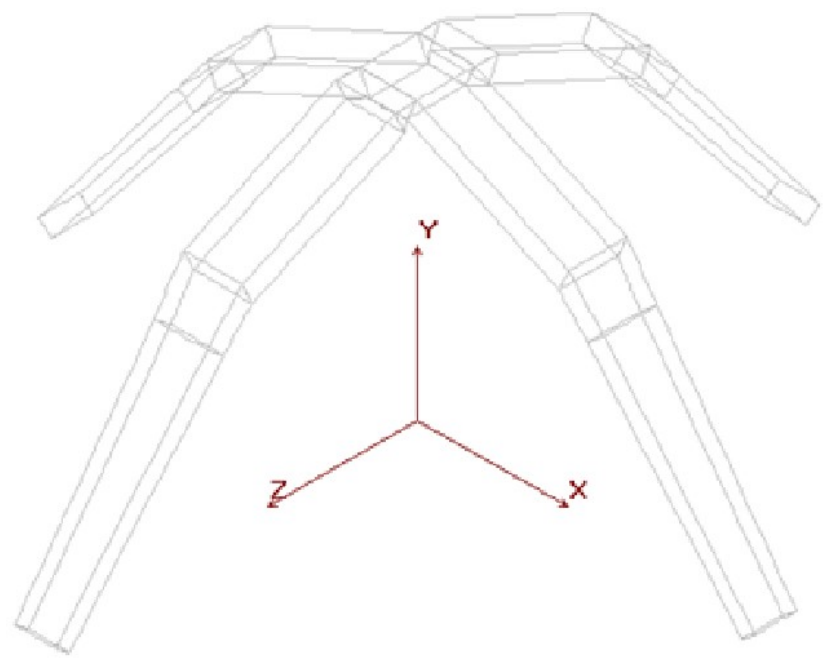

Fig. 5 Structural model of the subassembly of workpieces connected to the actuator, $3 \mathrm{~d}$ model

The material of the bars of the structural model of the garv rotor subassembly works (except for some accidents) only in the linear elastic field. Consequently, the material is characterized by the following three constants: the modulus of linear elasticity, $E=2.1 \cdot 10^{11}$ $\mathrm{N} / \mathrm{m} 2$ the transverse contraction coefficient, $v=0.29$ and the mass density, $\rho=7850 \mathrm{~kg} /$ $\mathrm{m}^{3}$. The inertial constants of the sections of the three types of bars used (ring bar, knife top bar and knife bottom bar) are given in table 1 .

Table 1 the inertial characteristics of the bar sections of the structural model in fig.2-3.

\begin{tabular}{|l|r|r|r|}
\hline Characteristic & $\begin{array}{l}\text { Ring bar, circular } \\
\text { crown profile with a } \\
\text { diameter of 40 mm } \\
\text { and a thickness of } 4 \\
\mathrm{~mm}\end{array}$ & $\begin{array}{l}\text { The upper part of the } \\
\text { knife, rectangular } \\
\text { profile 50x20 mm }\end{array}$ & $\begin{array}{l}\text { Bar of the lower part } \\
\text { of ther knife, } \\
\text { rectangular } \\
35 \times 15 \mathrm{~mm}\end{array}$ \\
profile \\
\hline Area of the section, $\mathrm{m}^{2}$ \\
$\begin{array}{l}\text { Moment of inertia Iy, } \\
\mathrm{m}^{4}\end{array}$ & $4.521599 \cdot 10^{-4}$ & 0.001 & $5.25 \cdot 10^{-4}$ \\
\hline $\begin{array}{l}\text { Moment of inertia Iz, } \\
\mathrm{m}^{4}\end{array}$ & $7.415422 \cdot 10^{-8}$ & $2.083333 \cdot 10^{-8}$ & $9.84375 \cdot 10^{-9}$ \\
\hline Depth of section, $\mathrm{m}$ & $7.415422 \cdot 10^{-8}$ & $3.333333 \cdot 10^{-8}$ & $5.359375 \cdot 10^{-8}$ \\
\hline Section width, $\mathrm{m}$ & 0.04 & 0.05 & 0.035 \\
\hline
\end{tabular}

For the 1D and 3D structural models shown in fig (3-5), the forces are applied on the faces of the working organs that interact frontally with the ground, and on the support of the structures it is done by cancelling all degrees of freedom (three translations and three rotations), in the upper part of the structure. The forces are applied to the faces of the working body that interact frontally with the ground. The tensile strength is intensely variable over time, so it, for static analysis, we applied an average on each organ, taking into account the fact that the four working organs move in uncultivated soil on a single already fully processed. The theoretically calculated forces have been corrected to achieve the total traction force and the total power consumed in experimental tests of the rotary agricultural harrow tractor with vertical axis rotors. In this valuable way for the 1D model, 
they are distributed in 9 nodes on each knife, and for the $3 \mathrm{~d}$ model on all the nodes of the faces exposed to the frontal presence of the ground.

In fig.6, is represented the distribution of the reaction forces in the fixing nodes of the structures, located on the ring. The maximum value of $1109.2 \mathrm{~N}$ is reached in the bearing points. As it is observed the application of some pairs of strong structures as a whole, it leads to higher forces in the bearing points. This fact draws attention to the need for projects and the realization of safe mobile couplings in order not to wear them prematurely and / or to produce work accidents with possible very serious consequences.

Fig.6 Reactions at the fixing points of the knives on the ring, in $\mathrm{N}$

\section{Results and discussion}

The results of loading the structural model of the vertical subassembly are: the relative displacement resulting in the structure, having the maximum value $0.00013 \mathrm{~mm}$, located at the free ends of the knives, the maximum equivalent tension, with the value $18.831 \mathrm{MPa}$, located on the knives, in the vicinity of the connection area . support ring. The maximum value of $1109.2 \mathrm{~N}$ is reached in the bearing points. As can be seen from the application of pairs of strong structures as a whole, it leads to higher forces at the support points.

A result obtained using the three-dimensional model is the fundamental eigenfrequency with the level $121.716 \mathrm{~Hz}$ and the next eigenfrequency of the structures, with the value $137.628 \mathrm{~Hz}$. These natural frequencies are useful in the design calculation, but especially in the calculation of improving the intensity of intense vibrations that can be generated by resonance phenomena. When making this statement, we take into account the values that can reach, for example, the speed of the rotor (higher than those used in the experiments we performed). 


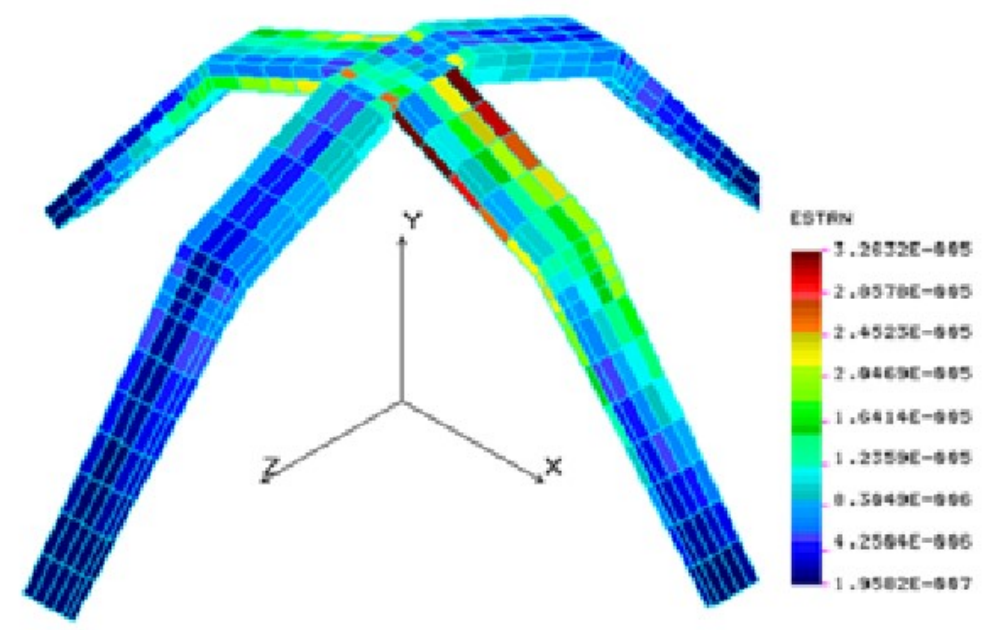

Fig. 7 Distribution of the total strain field on the boundary of the structure analyzed in 3D model

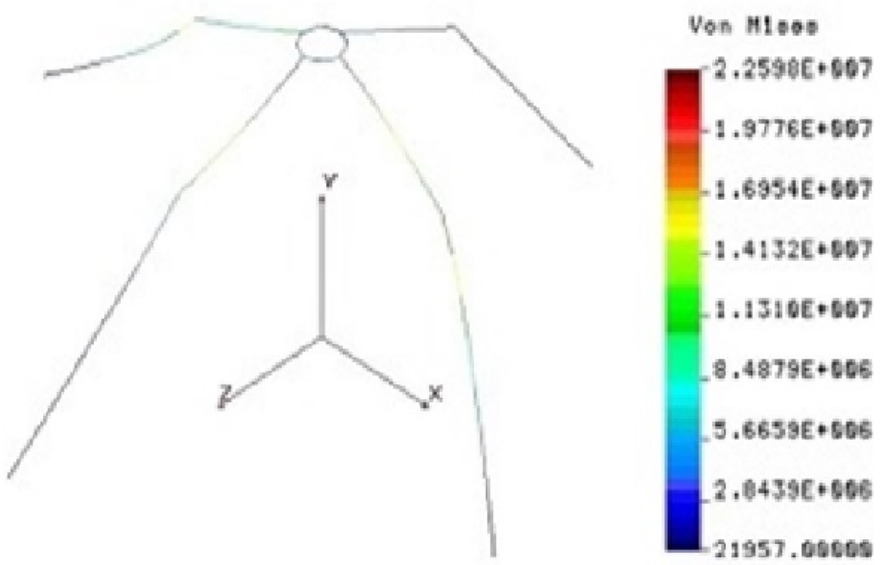

Fig.8 Equivalent stress state (Von Mises) in the structural model, in Pa in the 1D model. 


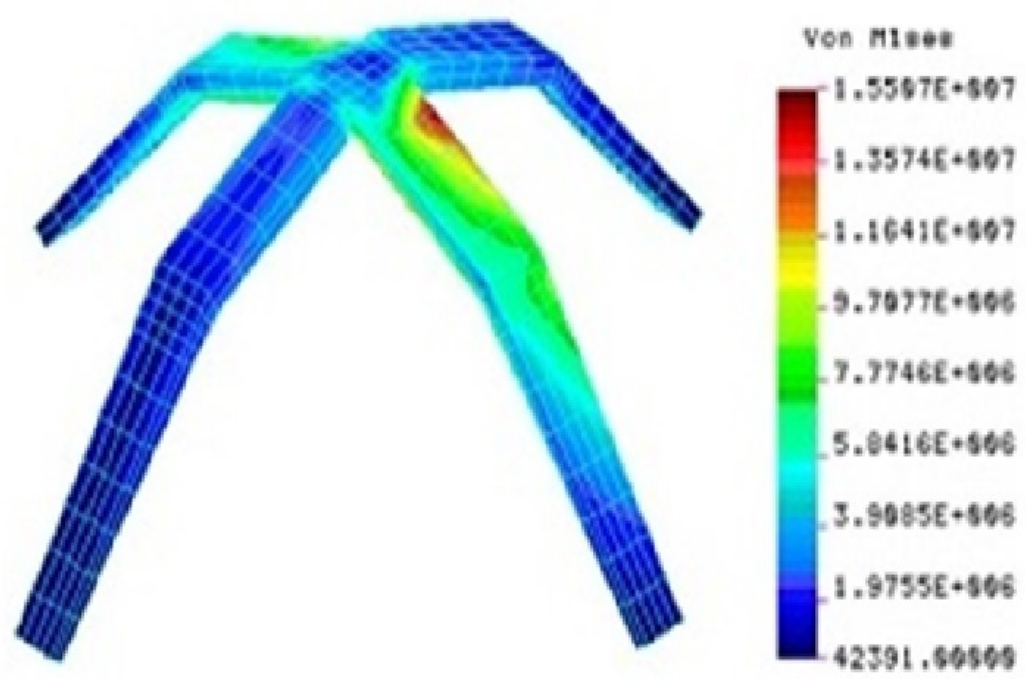

Fig.9 Diastribution of the equivalent stress field on the boundary of the structures, in $\mathrm{Pa}$ in 3D model

In order to compare the results obtained by the $1 \mathrm{D}$ and $3 \mathrm{D}$ methods, the distribution of the equivalent stress is represented in fig 8 and 9 , obtaining the variant of the structural model $1 \mathrm{D}$ and respectively $3 \mathrm{D}$.

\section{Conclusions}

- the structural models proposed and solved with the help of the finite element method, provide useful information for the activity of conception and design of the modeled elements and subassemblies. The stresses and deformations in the analyzed structure can be estimated and thus the safety factor can be estimated, so their resistance. From this point of view, the analyzed structure is very correctly dimensioned, apparently even oversized. In general, however, given the inhomogeneity of the soil, its anisotropy and high peripheral speeds, violent shocks can occur in operation, which means an increase of over 2.5 times the applied force, possibly in much smaller areas than in the examples.

-in the presented models you can change materials, geometry, loading to simulate various phenomena. The model with $1 \mathrm{D}$ element admits the fastest change of the geometry of the section, requiring only the change of the inertial characteristics of the cross section.

-the analyzed models can be used to diagnose in operation some vibration regimes with resonance. The eigenfrequencies of the analyzed structure are obtained by analyzing the spectrum of own frequencies of the elements and subassemblies of the modeled physical structure (in our case the subassembly of working organs). In this concrete case, the working frequencies of the rotors $(17-22 \mathrm{~Hz})$ are very low comparing with the first two natural frequencies of the examined subassembly $(121.716$ and $137.628 \mathrm{~Hz})$.

-for the structural models built in this paper, it was considered that the material of the structures have an elastic linear behaviour. If the appearance of irreversible deformations is studied, then, materials with nonlinear properties must be considered rigidity of the structure and the theoretically estimated values of the forces, used in mathematical models, exclude the occurrence of the irreversible deformations in the structure.. 


\section{References}

1. M. Voicu, Teoria sistemelor, Editura Academiei Romane, (2008)

2. Foley, James D. (1996), "12.7 Constructive Solid Geometry", Computer Graphics:

Principles and Practice, Addison-Wesley Professional, pp. 557-558, ISBN 9780201848403

3. M. Li, Q. Zhang, H. Wang, H. Sun, J. Tong, A 3D FINITE ELEMENT SIMULATION ANALYSIS OF THE SOIL FORCES ACTING ON A ROTARY BLADE, Transactions of the ASABE (American Society of Agricultural and Biological Engineers) · January (2015) 4. Structural Research \& Analysis corp., COSMOS/M 2.7 CAD Interface User Guide, 2007Foote R. L., The Volume Swept out by a Moving Planar Region, Mathematical Magazine, Vol. 79, No. 4, 2006, pp. 289-297

5. Rades M., Analiza cu elemente finite, (2006)

6. Tolvaly-Rosca F., Pasztor J., Work process analysis of the machines with working parts entrained, in seedbed preparation works, INMATEH Agricultural Engineering, vol. 58, 9:16, No. 2 / (2019)

7. Cardei P. \&all, Structural analysis and materials focused on mechanics, mechatronics, maintenance and operation of machinery for agriculture and food industry, Terra Nostra Iasi publishing house, (2012)

8. ASABE (American Society of Agricultural and Biological Engineers, ASAE D497.7 MAR2011 Agricultural Machinery Management Data, Standard, (2011) 